\title{
IMPROVING STUDENTS' UNDERSTANDING OF ENGLISH SENTENCES THROUGH UNDERSTANDING OF SENTENCE PATTERNS
}

\author{
Mainar Fitri \\ State Islamic University of Sultan Syarif Kasim Riau, Indonesia \\ mayfitry81@gmail.com
}

\begin{abstract}
Based on the researcher's observation in teaching and learning process, there were some problems faced by the students in understanding of English sentences of different types of texts (genre). The problems consisted of: (1) The students did not know the key ideas and details of English sentences. (2) the students were not able to differentiate between key ideas and less important ideas in sentences. To solve those problems, it was important to do a class action research by using a strategy of understanding sentence patterns. There were 2 aims of this research. The first aim was to explain to what extent students' understanding of sentence patterns can better improve students' understanding of English sentences. Secondly, to explain what factors influence the changes of students' understanding of English sentences. This research consisted of three cycles. The result of the research showed that the strategy of understanding of sentence patterns could improve students' understanding of English sentences. The improvement could be seen from the students' average scores in the tests of understanding of English sentences which improved before the cycle into cycles. The average scores consisted of 28.7, 32.4, 56.4 and 60.6. the students' average score improved 3.7 in cycle $1,1.24$ in cycle 2 and 4.2 in cycle 3 . So, the improvement of understanding of English sentences before cycle into cycles was 31.9. So, it can be concluded that the strategy of teaching sentence patterns improves students' understanding of English sentences. It is caused by some factors. The factors are the teacher's treatment, classroom atmosphere and students' motivation in learning process.
\end{abstract}

Keywords: Improving Students' Understanding of English Sentences, Sentence Patterns

\section{A. Introduction}

Understanding English sentences is very important. To get the ideas what a writer expresses in his/her writing, a reader needs to understand what sentences are about, what happen in the sentences and what other specific information is written in the sentences. To know what the sentences are about, what happen in the sentences and what the specific or detail information is, the reader should be able to identify key ideas of all types of sentences in a text, 
locating details and identifying less important ideas.

According to the curriculum used at the time, KTSP Curriculum, the standard competence of reading skill for the eleventh grade of senior high school students is understanding different types of texts (genre) such as narrative, descriptive, hortatory exposition, analytical exposition and spoof. To understand the texts, students need to understand sentences constructing the texts. The importance of understanding the different types of sentences by students is stated in KTSP curriculum as indicators that must be taught by teachers to the eleventh grade of senior high school students.

Based on the researcher's observation, the eleventh grade of MA Hasanah had low capability in understanding English sentences. It was caused by two factors: The students themselves and the technique used by the teacher. Both were seen in teaching and learning process when the teacher asked the students to do exercises in understanding English sentences from a text. The researcher found that most of the students were not able to identify key ideas, details and less important ideas of sentences. The students' scores on the exercise showed that only 5 of 27 students could answer the key ideas of sentences, 2 of 27 students could locate details and none of them could identify less important ideas in sentences. This happened because most of the students did not know how to identify key ideas, details and less important ideas of sentences. Another cause was that the students did not know the meaning of words in sentences based on the context. Next, the students could not answer what the sentences are about and what happen in the sentences. And the last was the students did not know the specific information of sentences. when they were asked about some specific information of sentences such as when and where did something happen? How did it happen? Why? Most of the students could not answer such questions.

The technique used by the teacher in helping the students understand English sentences was still a traditional way; by consulting the meaning of difficult words of sentences into their dictionaries. This technique spent much time for the students to understand sentences because they should consult their dictionaries to find the meaning words by words of sentences. Furthermore, the students could not find the meaning of words based on the context. This technique made the students bored and less motivated because they looked up the dictionaries for every difficult word.

Based on the fact above, the researcher used a treatment to improve the students' understanding of English sentences and to help the English teacher to solve the problems mentioned above. The treatment was understanding of English sentences through understanding of sentence patterns. The researcher chose this treatment because through understanding sentence patterns, it is hoped that the students can get the ideas of sentences and can identify the key ideas and less important ideas of sentences and detail information from the sentences. The key ideas can be recognized from a subject and a predicate of a sentence. While the detail information can be recognized from a complement and modifiers. A reader can understand what the sentence is about and what happen by understanding the subject and the predicate of the sentences, the questions about the complement and modifiers as 
what, where, which, when how and why ask about the details or specific information.

English has some types of sentence patterns. By understanding different types of sentence patterns, it is hoped that the students can understand the different types of sentences. This treatment is based on the reading theories in understanding sentences supported by Zainil (2006) and McWhorter (1986). The other reason why the researcher chose this treatment is to help the students to understand different types of texts. To understand the texts, it is necessary to understand sentences of the texts, especially the topic sentence in each paragraph of the text. so, in this research, the researcher conducted a research on improving students' understanding of English sentence through understanding of sentence patterns at the eleventh grade of MA Hasanah Pekanbaru. However, the researcher formulated the research questions; to what extent can students' understanding of sentence patterns better improve students' understanding of English sentences at the eleventh grade of MA Hasanah and what factors influence the changes of students' understanding of English sentences.

\section{B. Review of the Related Theories \\ 1. Understanding of English Sentences}

A sentence is a group of words that is used to communicate an idea in writing or in speaking (Ann and Alice: 1978, 1980, 1981). Every sentence is composed or one or more clauses and expresses a complete thought. Clauses are the building blocks of a sentence and a clause is a group of words that contains at least a subject and a verb.
To understand sentences, Mc Whorter (1986) gives approaches. The approaches can help readers how to find important information in sentences, how to find less important ideas and see how ideas are connected. The approaches are identifying key ideas, locating details and identifying less important ideas.

\section{a. Identifying Key Ideas}

Every sentence expresses at least one key idea, or basic message. This key idea is made up of two parts, a simple subject and a simple predicate. The simple subject, usually a noun, identifies the person or subject the sentence is about. The main part of the predicate is a verb which tells what the person or subject is doing or has done. Usually, a sentence contains additional information about the subject and the predicate. For example; the average American drank six gallons of beer last year.

The key idea of the sentence is "American drank". It is expressed by a simple subject "American". It tells what the sentence is about. The word "the" and "average" give more information about a subject "American", by telling which one. The main part of the predicate of the sentence is "drank". This tells what the average American did. The rest of the sentence gives more information about the predicate by telling what and how much was drunk.

\section{b. Locating Details}

The second approach in understanding a sentence is to see how the details affect its meaning. Details usually answer such question about the subjects or 
predicate as what, where, which,

when, how or why, for example;

Sam drove $\frac{\text { his car }}{\text { What }} \frac{\text { to Toronto }}{\text { where }} \frac{\text { last week }}{\text { when }}$

c. Identifying Less Important Ideas

The next approach is identifying less important ideas. The less important ideas usually explain the key idea by describing, expressing cause, starting purpose or reason, describing conditions or circumstances or expressing time relationship. The less important ideas cannot stand alone. It does not have a sense when it stands alone. It always stands with key ideas which are related.

For example; After we left the party, we stopped for a pizza

Less Important Ideas Key Ideas

Basically, there are four kinds of sentences in English. They are simple sentences, compound sentences, complex sentences and compoundcomplex sentences (Alice and Ann: 1991). Each type of sentences has one or more key ideas and details.

Simple sentences consist of only one key idea, the rest is details. For example;

1. I enjoy playing tennis with my friends every weekend.

2. I enjoy playing tennis and look forward to it every weekend.

3. My friends and I play tennis and go bowling every weekend

From the example above, the key idea of sentence (1) is I enjoy. The key idea of sentence (2) is I enjoy and look forward. The key idea of sentence (3) is friends and I play and go. The rest of them are called details of the sentences.

Compound sentences consist of two key ideas joined together by sentence connectors and semicolon and conjunctive adverb. The two ideas are equally important. For example:

1. I enjoy playing tennis, but I hate playing golf

2. I enjoy playing tennis; however, I hate playing golf
3. I enjoy playing tennis: I hate playing golf

Complex sentences consist of more than one idea, but it only has one key idea. The other idea is less important idea. For example:

1. Although women could own properly, they could not vote. Or, women could not vote although women could own properly.

2. Men who are not married are called bachelors.

3. Scientist believe that the earth's temperature is rising.

The key idea of the sentence (1) is they could not vote; the rest is the less important idea. The key idea of sentence (2) is Men are called bachelors; the less important idea is who are not married.

Compound-complex sentences consist of more than one key ideas joined together with the less important ideas. For example; after I graduated from high school, I wanted to travel, but I had to work. The key ideas of sentence are I wanted to travel and I had to work in family's business. The less important idea is after I graduated from high school.

In conclusion, understanding English sentences means understanding 
the ideas of English sentences. So, to comprehend or to understand the ideas of various sentences such as simple sentences, compound sentences, complex sentences and compoundcomplex sentences can be done by identifying key ideas of each type of sentences, locating details/additional information and identifying less important ideas. The key of sentences describes what the sentences are about and what happen, details describe additional information, and the less important ideas join with the key ideas in complex sentences and compoundcomplex sentences.

\section{Understanding of Sentence Patterns}

1. The Concept of Sentence Patterns

De Boer (1973) states that sentence patterns are formulas used by grammarians to illustrate the design of basic English sentences. Glatthon (1980) states that it is necessary to understand sentence patterns by understanding some important parts of speech and sentence parts. The parts of speech are the grammatical classes to which words belong. The sentence parts are the parts of sentences which do different job. The parts of the sentences consist of:

a. Noun: a name of person, place or thing

b. Pronoun: a word which takes the place of noun

c. Verb: a word showing action or being

d. Transitive Verb: a verb which takes an object

e. Intransitive Verb: a verb which does not take an object

f. Be Verb: the verb be and its forms (being, was, am, etc)

g. Linking Verb: verb of sense (seem, touch, feel, etc) h. Adjective: a word which modifies a noun or pronoun

i. Adverb: a word which modifies a verb

j. Conjunction: joining words (and, but, because, etc)

k. Preposition: a word which shows a relationship (in, to, for, by, etc)

1. Determiner: a word which signals a noun such as a, an, the, etc.

Glatthorn (1980) also states that the following word classes are the parts of speech which are used as sentence parts.

a. Simple subject: the naming part of the sentence; the person, place, thing that the sentence is about.

b. Simple predicate: the action part of the sentence; the word that tells what the subject is/was doing.

c. Direct object: the person, place, or thing to which the direct object was sent or was given.

d. Complement: a part of the sentence which follows the verb be or linking verbs, which completes the sense of the sentence; include predicate nominative (a noun following the verb be) and predicate adjective (an adjective following the verb be or linking verb) an adverb can also be used a compliment after be.

Sentence patterns are like maps of sentences. Patterns show the different parts of basic sentences. The patterns also show how these parts go together so that the sentence makes sense. The most essential parts of written sentences are the subject and the predicate. The subject and the predicate are the parts that allow written sentences to make sense when they stand alone. Some basic sentences also have objects and complements. These parts may be needed to make the meaning of the sentence complete. 
Understanding sentence pattern is very necessary to know the structure of each type of sentences. The basic sentence patterns are sentences that consist of a subject and a verb or predicate. A subject means to whom or what something happens. A predicate is what happens (Zainil: 2006, 22). A sentence is not complete when it consists of only a subject or only a verb. So, a complete sentence must have both, a subject and a verb, while the more complete sentences consist of a subject, a verb and complements or modifiers of the subject and the predicate. A subject of a sentence is usually a noun identifying the person or object the sentence is about. A predicate of a sentence is usually a verb. It refers to what the person or object is doing or has done. A sentence usually contains additional information about the subject and the predicate.

George studied for three hours last night

$$
\mathrm{S} \mathrm{V}
$$

Kathy lives in Boston near the waterfront

$$
\mathrm{S} \mathrm{V}
$$

Food prices have risen drastically in the past four years.

$\mathrm{S}$

Some sentences may have more than one subject or more than one verb which is called compound sentences. For examples:

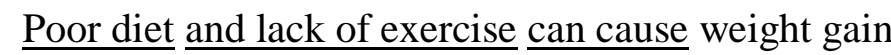

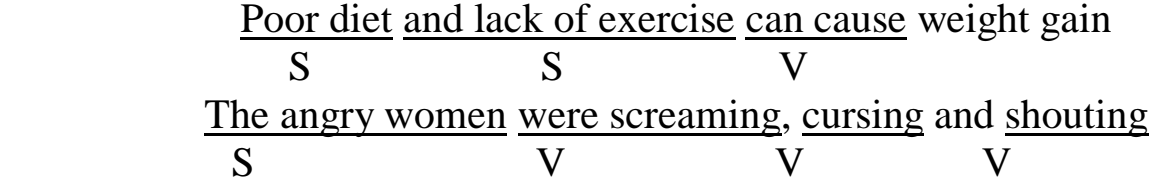

According to Glatthorn (1980) there are some basic patterns of English sentences.

a. $\mathrm{N}+\mathrm{V} 1$

For example: Fire burns

b. $\mathrm{N}+\mathrm{V} 1+\mathrm{N}$

For example: We ate the Popcorn

c. $\mathrm{N}+\mathrm{V} 1+\mathrm{N}+\mathrm{N}$

For example: Gary sent this brother a car

d. $\mathrm{N}+\mathrm{LV}+\mathrm{N}$

For example: Ben becomes a president

e. $\mathrm{N}+\mathrm{LV}+$ adjective

For example: The cheese smelled rotten.

f. $\mathrm{N}+\mathrm{Be}+\mathrm{N}$

For example: Stephen is a Captain

g. $\mathrm{N}+\mathrm{Be}+$ Adjective

For example: Mary is happy

h. $\mathrm{N}+\mathrm{Be}+$ Adverb

For example: The students are in the classroom
De Boer (1973) states that each basic pattern of sentences has characteristics and classification. Verbs have characteristics and classification as follow:

a. Verbs may change form to show a change on tense, mood, voice, number, and person.

b. Verbs are classified into two main groups: transitive and intransitive. Transitive verbs require a receiver for their action and intransitive verbs do not.

c. In the sentence the verb serves as the simple predicate which makes a statement, asks a question, makes a request or given a command concerning the subject.

d. Simple predicate may be a single word, or a group of two or more words acting as unit. If a word group performs the job of predicate. It is called a verb phrase which 
consists of a main verb plus one or more auxiliaries (helping verbs). There are twenty-three auxiliaries which may combine with verbs of action or condition to form a verb phrase: is, am, are, was, were, be, being, been, do, did, have, has, had, may, can, might, could, would, should, shall, will, must.

e. Eight of the auxiliaries may be used as linking (intransitive) verbs, and may appear in sentences alone or with auxiliaries of their own. They are: is, am, are, was, were, be, being, been. Other verbs are often used as linking verbs appear, taste, feel, look, become, grow (when it means become), remain, seem, smell, sound.

f. The parts of verb phrases may be separated in a sentence.

g. A verb or phrase serving as a simple predicate may be compound.

2. A noun has characteristics and classification as follow:

a. It may be inflected (change form) to become plural.

b. It changes form (is inflected) to indicate possession.

c. It is often preceded by one more determiners.

d. Certain group of nouns have typical ending (derivation suffixes) such as -tion, - ure, ance, - ment which distinguish them from corresponding verb and adjectives.

e. It occurs in certain set positions in normal English word order.

f. A common noun names any one a class of person, place, or things.

g. A proper noun is a name applied to specific person, place, or things. h. A collective noun is a name applied to a group.

i. A concrete noun is a name applied to something that can be perceived by one or more of the sense.

j. An abstract noun is name applied to a quality or a general idea.

k. A compound noun is one made up of two or more words.

1. A noun or any word or group of words used as a noun is a called a substantive.

3. A pronoun has characteristics and classification as follow:

a. A pronoun is word used in place of a noun.

b. Personal pronoun indicated (1) the speaker (first persons); (2) the one spoken to (second person); (3) the one spoken of (third person).

c. Interrogative pronouns ask question.

d. Relative pronouns are both pronouns and connectives (connecting words)

e. Demonstrative pronouns point out.

f. Indefinite pronouns do not point out do definitely as demonstratives do.

g. Compound personal pronouns (the self-pronouns) have uses: (1) as intensive pronouns (to emphasize) or (2) as reflexive pronouns (to refer to the subject).

4. Adjective have characteristics and classification as follow:

a. It may be inflected (change form) to make comparisons.

b. It is represented by the A in sentence pattern 4 .

c. It may have a derivational suffix which helps to identify it. 
d. Determiners are adjective words that limit, or in some way signal, nouns.

They are also called "noun marker".

(1) The articles; a, an, and the are determiners which point out definitely (the) or indefinitely (a, an).

(2) Certain (sometimes

pronouns pronominal) called determiners.

(3) Numerals, both ordinal and cardinal, may be determiners.

(4) Both common and proper nouns may be used as determiners.

(5) Possessive nouns, both common and proper, may be determiners.

e. Certain combination of noun, verb, adverb, and adjective form may be used as noun modifiers.

f. An adjective used as an objective complement follows the direct object that it modifiers.

g. Adjectives are sometimes classified according to their position.

h. Prepositional phrases function as noun modifiers in the same way that single-word adjectival words do.

i. Participles and participial phrases are noun modifiers.

j. Infinitives and infinitive phrases may be used as noun modifiers.

5. Adverbs have characteristics and classification as follow:

a. Adverbs are form class words that modify other word pin sentence. b. Adverbs have been traditionally classified as adverbs of manner, time, place, degree, and cause.

c. Adverbs have mobility as modifiers.

d. Not is a negative word that is really a sentence modifier.

e. Adverbial objectives are noun used as adverbs.

f. Prepositional phrase may be used as adverbs.

g. An infinitive or an infinitive phrase may be used as an adverb.

h. Indirect object is really the object in adverbial prepositional phrase in which the preposition is understood.

i. Adverbs and adverb phrases may modify participle or infinitives.

j. Many adverbs are formed by adding -ly to descriptive adjectives.

k. Often adjectives and adverbs have the same form.

1. Most adverbs can be compared.

m. For some adverbs that are not formed from adjectives, use er and est to form the comparative and superlative.

n. Use irregular forms in comparing certain adverbs.

Each type of sentences has different patterns to each other. Firstly, simple sentence. The pattern of simple sentences, as Alice and Ann (1991) state, that a simple sentence is an independent clause. An independent clause has a subject and a verb and expresses a complete thought. It can stand alone as a sentence by itself. An independent clause is like an adult person; it is independent and can live by itself. An independent clause is formed with: Subject + Verb ( + Complement). 
The followings are the examples of simple sentences:

a. I enjoy playing tennis with my friend every weekend.

b. I enjoy playing tennis and look forward to it every weekend.

c. My friends and I play tennis and go bowling every weekend.

All of the examples above are simple sentences. Each of them is an independent clause. They have a subject or more than one subjects and one or two verbs but they are only one clause. On example "a", the simple sentence consists of one subject and one verb. On example " $b "$ ", the simple sentence consists of one subject and two verbs "enjoy and look forward to" then it is called a compound verb. On example "c", contains two subjects "my friend and I" and two verbs "play and go" but it has only one clause, it is called simple sentence with a compound subject and a compound verb.

For compound sentences, they consist of two or more independent clauses joined together. Each clause has equal importance and could stand alone. There are three ways to join independent clause to form a compound sentence. First, join two or more independent clauses with a coordinator. Second, join two or more independent clauses with conjunction adverb. Third, join two or more independent clauses with a semicolon. Look at the following examples. All of them are compound sentences.

a. I enjoy playing tennis, but I hate playing golf. (Join independent clauses with a coordinator). Compound sentences with coordinators can be formed with independent clause + Coordinator + independent clause. There are only seven coordinators that can be used: for, and, nor, but, or, yet, and so. b. I enjoy playing tennis; however, I hate playing golf. (Join independent clause with a conjunctive adverb). A compound sentence with conjunctive adverbs can be formed with: independent clause; Conjunctive Adverb, + independent clause. The conjunctive adverb used such as furthermore, however, otherwise, and therefore.

c. I enjoy playing tennis: I hate playing golf. (Join independent clauses with a semicolon). This kind of sentence occurs when the two independent clauses are closely, separated. If they weren't related, they would be written as two simple sentences, separated by a period.

A complex sentence consists of one independent clause and one or more dependent clauses. In a complex sentence, one idea is generally more important than the other one. The more important idea is placed in the independent clause and less important idea is placed in the dependent clause. There are three types of dependent clauses used in a complete sentence: a dependent adverb clause, a dependent adjective (relative) clause, and a dependent noun clause.

A dependent adverb clause begins with an adverbial subordinator such as when, while, because, even though, so that, if, etc. There are two possible positions for a dependent adverb clause before or after the independent clause. A comma is used if a dependent adverb clause comes before the independent clause but no comma is used if the dependent adverb clause comes after the independent clause.

A dependent adjective (related) clause begins with a related pronoun such as who, whom, which, whose, where, when and why. A dependent adjective clause functions as an adjective modifying a noun. 
A dependent noun clause begins with a Wh-question word, whether and if. A noun clause functions as a noun; as a subject or an object.

Look at the following examples:

a. Although women could own properly, they could not vote. Or, women could not vote although women could own properly.

b. Men who are not married are called bachelor.

c. Scientists believe that the earth's temperature is rising.

A compound-complex sentence is a combination of two or more independent clauses and one or more dependent clauses. The followings are the examples of compound-complex sentences.

a. After I graduated from high school, I wanted to travel, but I had to work in my family's business.

b. Although women could own property, they could not vote, nor could they be elected to public office.

Different types of sentences have different patterns. By understanding the patterns of sentences, someone can identify the type of sentences. The following is the sentence pattern in English on the different types of sentences (Alice and Ann; 1991).

a. Simple Sentence

b. Compound Sentences

$$
\mathrm{S}+\mathrm{V} \text { + Complement }
$$

$$
\mathrm{S}+\mathrm{V} \text { Complement + Connectors }+\mathrm{S}+\mathrm{V}
$$

c. Complex Sentences

$\mathrm{S}+\mathrm{V}+$ dependent clause (noun clause, adjective clause and adverb clause).

d. Complex-Compound Sentences

$$
\mathrm{S}+\mathrm{V}+\text { Connector }+\mathrm{S}+\mathrm{V} \text { + Dependent clause }
$$

Understanding sentence patterns means recognizing or identifying the patterns of the four types of sentences, simple sentences, compound sentences, complex sentences and compoundcomplex sentences. The patterns of the sentences consist of subject, verb, complement, coordinators/conjunctive adverb/semicolon, and dependent clause (noun clause, adjective clause and adverb clause).

\section{b. Communicative Language Teaching of Sentence Patterns.}

Communicative language teaching is a theory of language teaching that starts from a communicative model of languages, language use, and that seeks to translate his into a design for an instructional system (Richards and Rogers: 1994).
They also stated about some characteristics of communicative view of language. First, language is a system for expression of meaning. Second, the primary function of language is for interaction and communication. Next, the structure of language reflects its functional and communicative uses. Finally, the primary units of language are not merely its grammatical and structure features but categories of functional and communicative meaning.

Hymes (1972) defined that knowing a language involves more than knowing a set of grammatical, lexical and phonological rules. In order to use language effectively, learners need to develop communicative competence.

Teaching English nowadays should be oriented on teaching communicatively. Teaching 
communicatively focuses on use not on usage or forms, the rules or patterns are taught based on the context and function, not isolated from the context. So, teaching sentence patterns does not focus on the patterns themselves but engages them with the functions and meaning. In this case, identifying a subject and predicate of sentences has a function to express the key ideas of sentences from which readers know what happen in sentences and to whom or to what something happens.

\section{Methods of the Research}

This research was a classroom action research. Hensen, et al (1996;1997) in Johnson (2005) defines that action research as the process of studying a real school or classroom situation to understand and improve the quality of actions or instructions. So, in conducting this research, the research studied her own classroom. She wanted to improve the student's understanding of sentences by doing actions; understanding sentence patterns. Improving student's understanding of the English sentences through understanding of sentence patterns was a classroom action research through which the researcher improved the students' understanding of English sentences by doing some actions in her classroom as a technique or a treatment to solve the students' problem in understanding English sentences. Furthermore, by conducting this research, the researcher tested whether or not this treatment or the technique better improved the students' understanding of English sentences. In conducting this research, there were three stages the researcher did to find out whether understanding sentence patterns better improved students' understanding of English sentences. The stages were plan, action and observation and reflection.

The location of this research was at MA Hasanah Pekanbaru. It is located on Cempedak street No. 37 Pekanbaru. The participants of this research were the eleventh-grade students of MA Hasanah Pekanbaru in academic year 2007/2008. The students consisted of one class with 27 students. The other participant of this research was an English teacher. She was the collaborator in this research. She also teaches at MA Hasanah Pekanbaru.

The research herself was as an instrument. She involved in the classroom activities to get data. She used test, observation and field notes. The tests were understanding of English sentence that asked about key ideas, locating details and identifying less important ideas in sentences. The tests were used to see the students' achievement in understanding English sentences. The tests were given to the students before cycle and after doing actions of each cycle to see the students' improvement in understanding English sentences and there were three cycles in this research. The following is the table of indicators of understanding of English sentences. 
Table 1. Indicators of Understanding of English Sentence

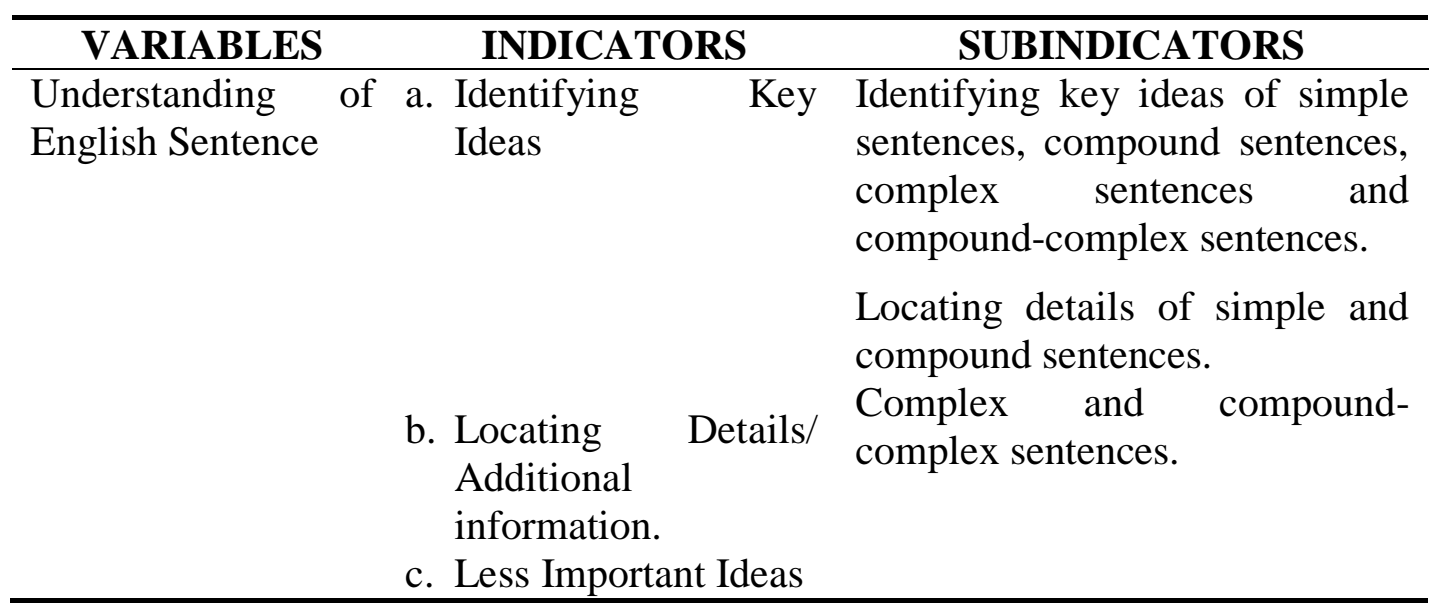

The test consisted of eight questions. Four questions asked about identifying key ideas of the four types of sentences; simple sentence, compound sentence, complex sentence and compound-complex sentence. Two questions asked about locating details and two question asked about identifying less important ideas.

The tests of understanding of English sentence on each cycle were analyzed by using simple quantitative data analysis. The following is the formula of simple quantitative data.

Score of sentence comprehension:

$$
\text { Score }=\frac{\text { Correct Answer }}{\text { Total Items }} \times 100
$$

The score was categorized into five levels;

$\begin{array}{ll}90-100 & : \text { Excellent } \\ 75-89 & : \text { Good } \\ 65-74 & : \text { Fairly Good } \\ 55-64 & : \text { Fair } \\ 0-54 & : \text { Poor (Sudjana, } \\ 1986: 38) & \end{array}$

To analyze the data of observations and field notes, quantitative analysis is used. There are six steps to analyze the quantitative data; data managing, reading/memoing, describing, classifying, interpreting, representing the findings or writing the report (Gay: 2000 : 239)

\section{The Research Findings}

This research was a classroom action research. It was conducted in three cycles. Each of the cycles consisted of three steps: plan, action and observation, and reflection. In addition, each cycle consisted of two teaching sessions. This research was held from May $15^{\text {th }}$ to June $5^{\text {th }}, 2008$. The schedule of teaching English was twice a week, on Tuesday and Thursday. So, there were six meetings, each meeting consisted of 80 minutes. The first cycle was conducted on May $15^{\text {th }}$ and $22^{\text {nd }}$, the second cycle was on May $27^{\text {th }}$ and $29^{\text {th }}$, and the third cycle was on June $3^{\text {rd }}$ and $5^{\text {th }}, 2008$.

\section{Cycle 1 \\ a. Plan}

To solve the students' problems in understanding English sentences, the researcher and her collaborator planned some activities and used a treatment to improve students' understanding of English sentences. The treatment was understanding sentence patterns. The plans designed in the first cycle consisted of: 
1. Preparing sentences from a text used as teaching materials.

2. Designing activities to understand English sentences through understanding sentence patterns which was described in lesson plan. follows:

The activities were planned as

Steps 1 (Pre-Activities)

a. The teacher stimulated students to think and mention the pattern of the sentences given.

b. The teacher asked the students to differentiate the four types of sentences given.

c. The teacher asked the students to identify a subject, verb complements, connectors, conjunctive adverb, semicolon, dependent clauses of sentences given.

d. The teacher asked the students to mention the function of the subject, the verb complements, connectors, conjunctive adverb, semicolon and dependent clauses in sentences.

Steps 2 (While-Activities)

a. The teacher introduced the patterns of the four types of sentences: simple sentences, compound, complex and compound-complex sentences by giving examples.

b. The teacher gave the model to the students in identifying a subject, a verb, complements, connectors, conjunctive adverb, semicolon, dependent clauses and mentioned the functions of them.

c. The teacher explained the differences of the four sentences one to another.

Step 3 (Post-Activities)

a. The teacher asked the students to sit in pairs. b. The teacher asked them to identify subject, verb, complements, connectors, conjunctive adverb, semicolon and dependent clauses and identify each type of the sentences given.

c. The teacher gave the students a test by asking them to identify the key ideas and details, and less important ideas.

b. Action and Observation

In this step, the researcher as a teacher conducted actions and observation with her collaborator. The researcher applied activities that she had planned before as stated in the previous step.

c. Reflection

Based on the observation and the field note, the majority of students paid attention to the lesson seriously, participated in pair group and class discussion, however, the students had weaknesses in identifying sentence patterns. They did not know to identify subject, verb, complement, connectors and dependent clause. They did not master the parts of speech positioned as subject, verb, complements and dependent clause.

\section{Cycle 2}

Based on the reflection in the first cycle, the researcher found some problems the students faced in understanding English sentences through understanding sentence patterns. The problems were:

1. The majority of the students were not able to identify key ideas and less important ideas in complex sentences.

2. The majority of the students were not able to identify the less 
important ideas in compoundcomplex sentences.

3. The majority of the students were not able to identify the main subject and the main verb.

4. The majority of the students still did not know the parts of speech functioning as subject, verb, complement, connectors and dependent clauses.

To solve those problems above, the researcher and her collaborator tried to find the solutions. They had some plans to solve the problems.

1. The teacher discussed with the class the definition of subject and verb, complement, connectors and dependent clause, what words could replace the position of subject, verb and others and their characteristic.

2. The teacher discussed with the class the characteristic of simple, compound, complex, compound- complex sentences and how to identify the key ideas, details and less important ideas in sentences.

\section{Cycle 3}

Based on the reflection in the second cycle, the researcher implemented the plan as described above. After doing observation, actions and reflection in the third cycle, the result showed that the students still had difficulties in understanding English sentences. It was caused by the students lack of mastery of sentence patterns especially the patterns of compound, complex and compound-complex sentences.

The followings are the research results of each cycle. Based on the results of the research of each cycle, it was found that the students' understanding of English sentences improved. It can be seen from the students' average score of the tests from one cycle to the next cycle.

Table 2. The Comparison of The Students' Average Score of Each Cycle

\begin{tabular}{cc}
\hline Cycles & Average Scores \\
\hline Before cycle & 28,7 \\
1 & 32,4 \\
2 & 56,4 \\
3 & 60,6 \\
\hline
\end{tabular}

The following is the graph of the average scores of students' understanding of English sentences

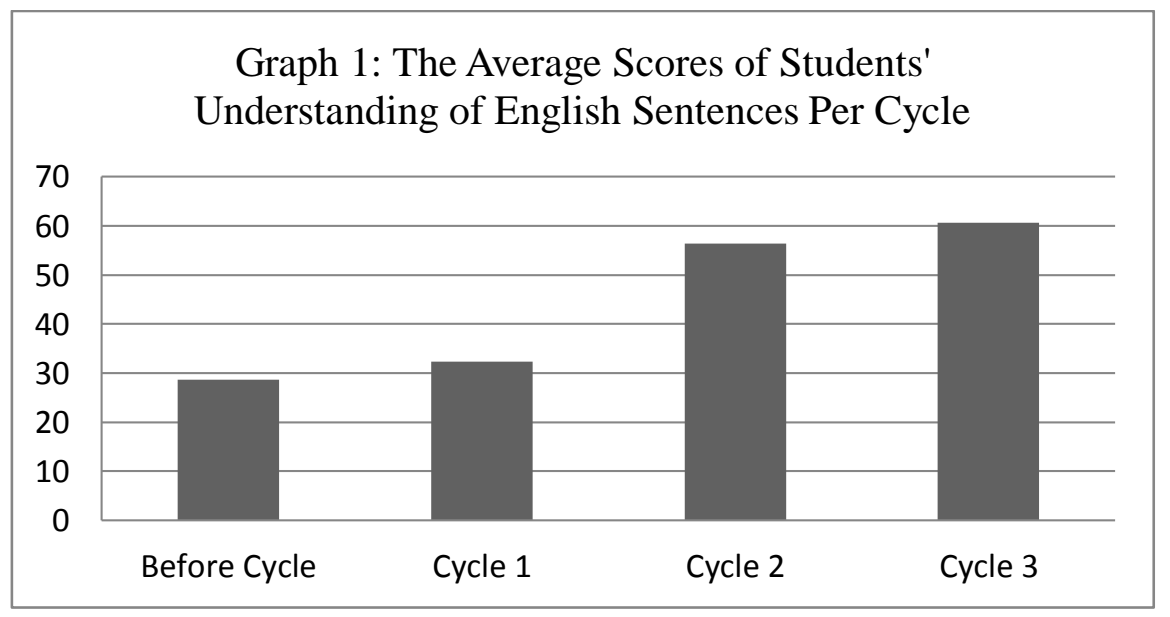


Based on the table and graph above, it is clear that the students' understanding of sentences through understanding sentence patterns improved from before cycle to the cycle 1 , from the cycle 1 to the cycle 2 and from the cycle 2 to the cycle 3 . The students' average score was 28,7 before the cycle, 32,4 in the first cycle, 56,4 in the second cycle and 60,6 in the third cycle. So, the students' average score improved 3,7 from before the cycle to the first cycle, 1, 24 from the first cycle to the second cycle and 4,2 from the second cycle to the third cycle. In general, the improvement of students' understanding of English sentences through sentence patterns from before the cycle to the last cycle was 31,9 . It means that understanding sentence patterns improves the students' understanding of English sentences.

The students' progress of understanding of English sentences per indicator of all cycles can be seen in the following table and graph.

Table 2. The Students' Average Scores in Understanding English

Sentences Per Indicators

\begin{tabular}{cccc}
\hline Cycles & Key ideas & Details & Less Important Ideas \\
\hline 1 & 18.5 & 12.5 & 1.4 \\
2 & 28.7 & 13.4 & 14.3 \\
3 & 30 & 17.1 & 13.4 \\
\hline
\end{tabular}

The students' progress of understanding of English sentences per indicator of all cycles can be seen in the following graph.

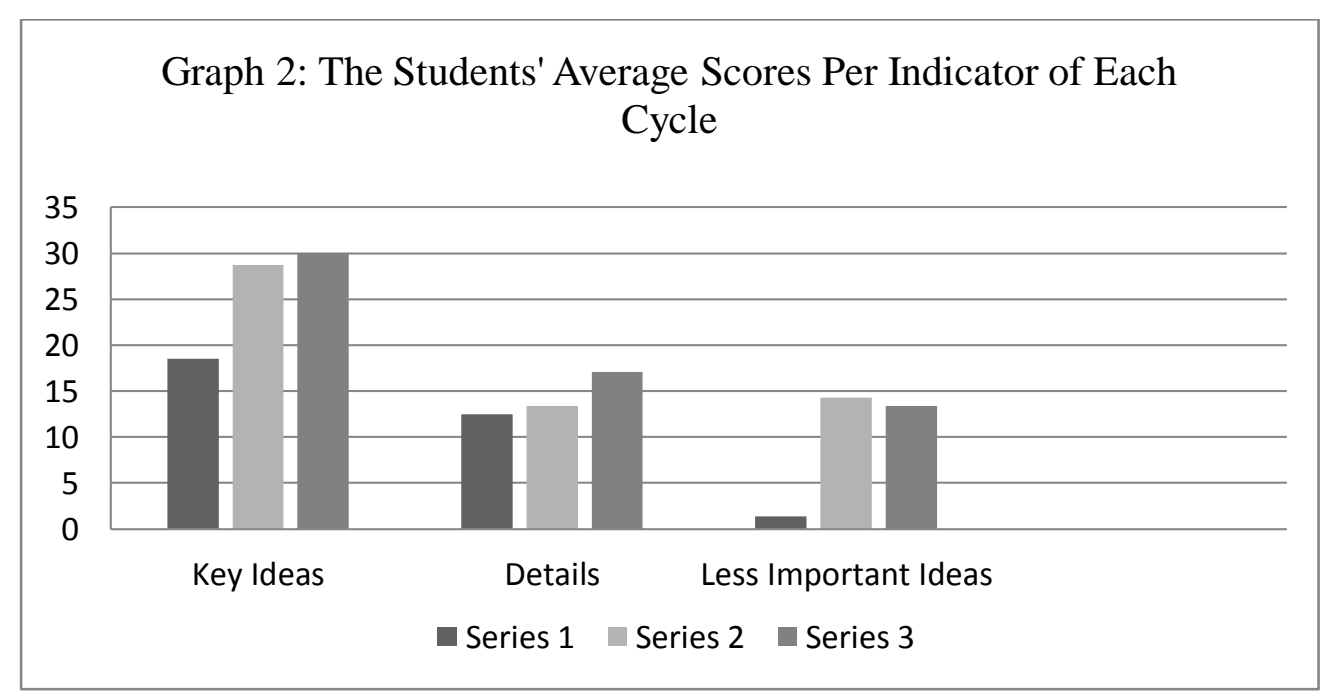

Based on the graph above, it can be seen that the students' ability in identifying key ideas increases in each cycle. In the first cycle, the students' average score was 18,5 , it improved in the second cycle; 28,7 and 30 in the third cycle. Besides, the average score of the students in locating details also improved in each cycle. The first cycle was 12,5 . Then, it improved 13,4 in the second cycle and 17,1 in the third cycle. In identifying less important, it improved from the first cycle to the second cycle; from 1,4 to 14,3 . However, it decreased in the third cycle. It was 13,4.

Based on the observation and field notes on each cycle, in general there were some factors influencing students' understanding of English sentences. 
Firstly, the teacher's treatment in the classroom. During the first and the third cycle, the students looked motivated to have class discussion and sat in pair instead of doing the exercises individually done in the second cycle. Besides, the teacher tried to solve the students' problems in understanding English sentences in each cycle through treatments. Secondly, classroom atmosphere. In the first and the third cycle, the classroom atmosphere was comfortable, it could help the students study more comfortable too; they could concentrate to the materials. On the other hand, in the second cycle, the classroom atmosphere was hot and it could influence the students' concentration in the lesson. Finally, the students' motivation. Based on the observation and field notes of the all cycles, it seemed that the students' motivation was influenced by classroom atmosphere and the teacher's treatment. When the classroom atmosphere was hot, the students less motivated to study. Furthermore, the time- study in the midday made the students lazy to study because of hunger, thirstiness and sleepiness. The teacher's treatment made the students motivated when they worked in pairs or in groups rather than individually.

In conclusion, the factors influencing the changes of the students in understanding English sentences through sentence patterns in each cycle as followed. In the first cycle, the factors consisted of the teacher's treatment in the classroom and the students' motivation. In the second cycle, the factors were the teacher's treatment in the classroom and the students' motivation and the teacher's treatment. In the third cycle, the factors were the teacher treatment and the students' motivation.

\section{E. Conclusion, Implications and Suggestions}

a. Conclusion

Based on the findings, the researcher concludes that:

1. Understanding of sentence patterns improves the students' understanding of English sentences at the eleventh grade of MA Hasanah Pekanbaru. In cycle one, the students' average score improved 3,7 . In cycle two, the students average score in understanding English sentence wass 1, 24 and it improved 4, 2 in the third cycle. So, the improvement of the students in understanding English before cycle into cycles was 31,9 .

2. There are some factors that influence the changes of the students' understanding of English sentences through understanding of sentence patterns:

a. The teacher's treatment

b. The student's motivation

c. Classroom atmosphere

\section{b. Implications}

The implications of this research in teaching English, especially in teaching understanding of English sentence are:

1. The result of this research showed that understanding of English sentence through understanding of sentence patterns improved students' reading comprehension of sentences at the eleventh-grade MA Hasanah Pekanbaru.

2. Understanding sentence patterns motivates the students of the eleventh grade at MA Hasanah Pekanbaru in learning English.

3. As an English teacher, the researcher uses the technique of understanding sentence patterns as 
one of choices in teaching English, especially in teaching reading comprehension of English sentences.

\section{c. Suggestions}

Based on the findings and the conclusions of this research, the researcher proposes some suggestions:

1. To have an ideal result of reading comprehension, the researcher suggests that the researcher as an English teacher should teach students to understand English sentences through understanding of sentence patterns communicatively.

2. The researcher as an English teacher at MA Hasanah Pekanbaru needs to develop the skills in teaching English so that achievement of the students always shows a significant improvement.

3. It is suggested for other teachers to do the next research related to the present research.

\section{References}

Andrews Richards. 2005. English Teaching and Practice. Knowledge about the Teaching of Sentence Grammar. The State of Play. Retrieved on Thursday January $1^{\text {st, }}$ 2009. http:www. Shurley.Com/pdf/ResearchResult. pdf.

Arfandi. 2005. The Contribution of Reading Strategy and Reading Techniques toward Reading Comprehension of Senior High School Students in Pariaman. A Thesis. Padang: Program Pascasarjana Universitas Negeri Padang.
Ary Donald, et al. 1972. Introduction to Research in Education. ( $\left.{ }^{\text {rd }} \mathrm{ed}\right)$. New York: Dryden Press.

Bensaoussan Marsha, and Batia Laufer. 1984. Journal of Research in Reading Lexical Guessing in Context in EFL Reading Comprehension $\quad \begin{array}{r}\text { (Retrieved } \\ \text { th }\end{array}$ February $\quad 15$ th ,2008)http:www.research in reading/research html.

De Boer, Jhon. J. 1973. Basic Language Messages and Meanings. Text and Grammar Handbook. New York. Harper \& Row, Publisher, Inc.

Gay L. R and Peter Airasian 2000. Educational Research. Competencies for Analysis and Application $\left(6^{\text {th }} \quad\right.$ ed). Ohio: Prentice Hall.

Glatthorn, Allan A, et.al. 1980. Composition Skills 3. The English Book. New York: Science Research Association Inch.

Gong Xue Ping. 1997. A Scheme for the Obtaining of Language Skills. (Retrieved on February $11^{\text {th }}$, 2009).

http:itesij/Articles/XuePing-Skills. Html.

Jhonson, Andrew P. A Short Guide to Action Research. (2 $2^{\text {nd }}$ ed). Mankato: Minnesota State University Press.

Kemmis, Stephen. 1988. The Action Research Planner. (3 rd ed). London: Deakin University.

McWhorter, Kathleen T. 1986. Guide to College Reading. Boston: Little Brown and Company.

McWhorter, Kathleen T. 1992. Efficient and Flexible Reading ( ${ }^{\mathrm{rd}}$ ed.) New York: Harper Collins Publishers Inc. 
Richards, C. Jack and Theodore S, Rodgers. 1994. Communicative Teaching, Foundation for Language Teaching. Patricia Henry

Royer, James Mike. 2006. Improve Reading Comprehension. (Retrieved on January $6^{\text {th }}$, 2008) http:wwwreadingsuccesslat. Com/glossary/improvereadingco mprehension.html.24k.

Oshima, Alice and Ann Hogue. 1991. Writing Academic English. A
Writing and Sentence Structure Handbook. ( $2^{\text {nd }}$ ed). Washington: Addison -Wesley Publishing Company.

Wikipedia. $2007 . \quad$ Reading Comprehension. (Retrieved on January $6^{\text {th }} \quad$, 2008) http:en. Wikipedia. org/wiki/reading.comprehension.i.

Zainil. 2006. Actional Functional Model (AFM). Padang: Universitas Negeri Padang Press. 